\title{
The Relationship between Mindfulness and the Mental Self-Boundary: Validation of the Boundary Protection Scale-14 (BPS-14) and Its Correlation with the Freiburg Mindfulness Inventory (FMI)
}

\author{
Klaus Blaser ${ }^{1}$, Milena Zlabinger ${ }^{2}$, Martin Hautzinger ${ }^{3} \&$ Thilo Hinterberger $^{2}$ \\ ${ }^{1}$ Centre for Applied Boundary Studies, Basel, Switzerland \\ ${ }^{2}$ Forschungsbereich Angewandte Bewusstseinswissenschaften, Abteilung für Psychosomatische Medizin, \\ Universitätsklinikum Regensburg, Germany \\ ${ }^{3}$ Psychologisches Institut, Universität Tübingen, Germany \\ Correspondence: Klaus Blaser, Centre for Applied Boundary Studies, Theodorskirchplatz 7, 4058 Basel, \\ Switzerland. Tel: 41-61-683-9852. E-mail: info@horizologie.ch
}

Received: November 6, 2013

Accepted: January 6, $2014 \quad$ Online Published: March 12, 2014

doi:10.5539/jedp.v4n1p155

URL: http://dx.doi.org/10.5539/jedp.v4n1p155

\begin{abstract}
The Boundary Protection Scale - 14 (BPS-14) represents a new instrument to capture the degree of protection of the mental self-boundary for use in mindfulness training, therapeutic work and scientific research. We assumed a relation between the ability to protect the self-boundary and mindfulness skills. For more efficient use the original version consisting 20 items was abridged and studied with regard to its validity and reliability. Also first reference values were calculated in a sample of 1,089 subjects, consisting predominantly of students. The total score of the abridged version with 14 items shows an acceptable reliability (Cronbach's $\alpha=0.79$ ) and a medium correlation $(r=-0.48)$ with mindfulness, measured by means of the Freiburg Mindfulness Inventory (FMI), regarding the convergent validity. Further studies are encouraged, as well as use of the BPS in mindfulness research, social neuroscience or everyday life.
\end{abstract}

Keywords: mindfulness, self-boundary, questionnaire

\section{Introduction}

The metaphor "mental inner world" for consciousness can be derived from modern neuroscientific and psychological findings as described by the neurophilosopher Metzinger (2009). He suggested the separation of the mental space into a self-model and a world model. Here, we use the terms inner world or intrapersonal space and outer world or extrapersonal space to describe this separation. The latter includes our surroundings but also our fellow humans. In this sense the self can be seen as an autonomous system, which can be regarded by an observer from the outside as a dynamic object and felt from within as "knower" of the subject, as described by Damasio (2010). Mindfulness can be described as a form of self-perception, as a reaction to inner experiences and as an approach to individual sensations and experiences (Siegel, 2007). The Tibetan expression for Buddhist is "Nangpa". "Nang" means "inside" and "pa" means "somebody"; somebody who is able to explore what is going on inside him/herself, somebody who can discover his/her own inner truth (Rinpoche, 2002). It describes a person who is able to look inside from within. Interoception determines an inner-world, in response to which a mindful person adopts a specific position. Mindfulness can be defined as returning to and dwelling in our innerworld with the location of our attention. If a psychic innerworld does exist, then a mental self-boundary also exists, which separates the individual innerworld from the outer world. It is in the nature of a boundary that it can be crossed in both directions. The means by which we can transcend our mental self-boundary is attention (Blaser, 2013). Attention is the process that shapes the direction of the flow of energy and information. Attention can be within consciousness, so we are aware of the object of our attention, or non-conscious, in that the energy and information flow are being directed but we are not aware of that flow (Siegel, 2012). To achieve a mindful mental state we enter our innerworld with the location of our attention. When the self-boundary is not well defined, is blurred for example by a trauma, we can no longer be sure if we are inside or outside our self-boundary with the location of our attention, that is, inside or outside our innerworld, mindful or not mindful. 
To illustrate the mechanisms of mindfulness and non-mindfulness the specific focus must be on the boundary between the mental self and the environment. The self-boundary constitutes the separating and connecting line between the individual self and the environment. It is the boundary where exchange between the inner and outer world takes place. In accordance with Luhmann (2002) systems must have permeable borders to incorporate compatible alterations from the environment and to thereby ensure their development and existence. That implies that the self-boundary should not only be protective but also receptive to stimulating, supportive and nurturing elements such as feelings and images.

In the spatial Boundary Awareness Model of Blaser $(2013,2012)$ the self-boundary has not only a filtering function from outside to inside, but also from inside to outside. Moreover it determines whether images and feelings belong to us or not. Here we point out how mental self-boundaries determine the capacity for mindfulness.

To be mindful, to look inside from within, we have to cross our self-boundary from outside to within with the location of our attention. When we arrive within ourselves, we are bodily connected with our emotions, experiences and images. When we now look outwards we are simultaneously aware of both the outside world and our bodily sensations. In this state of mindful awareness the space within merges instantaneously with the space outside, which is the essence of mindfulness.

Despite system theories, interpersonal neurobiology (Siegel, 2012) and neurobiological mindfulness research (Hölzel et al., 2011) etc., there was very little scientific attention paid to the self-boundary in the past. Luhmann (2002) writes that "system boundaries are definitions", which also applies to the self-boundary. Hartmann (1991) was one of the few who researched with the Boundary Questionnaire. He confined himself to the relationships between the permeability of the self-boundary and sleep duration, oneiric memories and daydreams. Although boundary violations were described (e.g. by Joraschky, 1996) as a consequence of traumata, intrusive interactions, exclusion, family secrets and other factors, there was no attempt to measure boundary changes.

An instrument which measures the permeability of the self-boundary or is able to compare the protective function of the self's system boundary is not only of diagnostic importance but also of great significance in the context of mindfulness in particular.Mindfulness training focused on the restoration of a protective and well-functioning self-boundary can be pursued, controlled and refined with a measuring instrument. With the questionnaire introduced here, the "Boundary Protection Scale - 14" (BPS-14), it will be possible to attempt serious scientific research into the self-boundary. This is of special relevance for mindfulness but is also important for psychiatry (Williams, Teasdale, Segal, \& Kabat-Zinn, 2007) and neurobiology (Hölzel et al., 2011).

Here, the design of the BPS-14 is presented along with the results for reliability, reference values and content validity. Further, we hypothesized that good boundary protection would go hand in hand with greater mindfulness and vice versa. Mindfulness is often described as a form of self-perception of inner experiences (Siegel, 2007). The various forms of interoception determine an inner world in response to which a mindful person adopts a specific position. The shift in perspective from the outer world to the inner world is only possible when a well-defined self-boundary exists (Blaser, 2013). Therefore, it could be hypothesized that a good boundary protection or boundary management serves as a precondition of mindfulness skills and vice versa. We therefore investigated potential correlations between the BPS-14 and the mindfulness factors of the Freiburg Mindfulness Inventory, not to test the factor structure of the FMI but to explore if the BPS-14 captures the wanted concept. In detail we expected a high correlation with the acceptance scale of the FMI that contains items - like "I am friendly to myself when things go wrong" - focusing the protection of the self from external influences.

\section{Methods}

\subsection{Materials}

BPS - Boundary Protection Scale: This questionnaire aims to capture the degree of protection provided by the individual self-boundary using 20 items in the long version and 14 items in the abridged one. Boundary refers to the mental delimitation of the self; for example, the ability to say "no" is an aspect of good boundary protection. The questionnaire investigates self-boundary functions such as permeability (items 1, 3, 5, 10 and 14), unwanted loading (items 12 and 13), retaining one's own energy (items 2 and 4), protection (items 7 and 8) and remaining within self-boundaries (items 6 and 9) (Blaser, 2008), resulting in a total score (numbers in brackets refer to the abridged version). A high score on this questionnaire indicates poor boundary protection, while a low score points to good boundary protection. Five possible answers are available, i.e. "almost never", "rarely", "occasionally", "frequently" and "almost always", which are assigned corresponding values from one to five. 
Items $6,7,8$ and 9 of the abridged version must be rated inversely. The abridged version (BPS-14) is shown in the Appendix.

FMI - Freiburg Mindfulness Inventory: This questionnaire by Walach and Buchheld (Walach et al., 2004) was applied in its short version with 14 items. Four possible answers are available, i.e. "rarely", "occasionally", "frequently" and "almost always", which are assigned corresponding values from one to four. A high score on this questionnaire indicates a high degree of mindfulness. Two subscales can be generated besides the global score; one is related to the ability to be present, named 'presence', and one relates to 'acceptance' of situations (Kohls, Sauer, \& Walach, 2009). The questionnaire has been validated in detail, showing a high internal consistency with a Cronbach's alpha of 0.87 (Walach et al., 2004).

\subsection{Procedure}

The questionnaires were digitized and made available online with the aid of the Software "EFS Survey" by the company Unipark (university program by Globalpark). The final survey contained the BPS-20 and the FMI as well as questions about the subjects' demographic characteristics and their experience with meditation, all in the German language. The questionnaire was available online for six weeks. No items were able to be skipped. We invited students and employees of the University of Tübingen via email to participate in our survey and to call up the webpage presenting this questionnaire. We offered the chance to win one of three vouchers (25€ each) to increase the motivation to participate. Furthermore the link was displayed on the webpage of the Center for Applied Boundary Studies (http://www.horizologie.ch) to gain a wider range of participants.

\subsection{Participants}

A total of 1089 participants completed the survey and could be included in the analysis. They were aged between 18 and 86 years (mean age 28.3 years, $\mathrm{SD}=10.6$ years); there were 263 males and 826 females. The sample was composed mainly of persons with higher education entrance qualifications, currently enrolled in vocational or university education, and graduates. More precisely, $68.3 \%$ were undergraduates and $24.2 \%$ were employees or civil servants. $28.7 \%$ of participants had had psychological therapy before, and $31.0 \%$ of those were in therapy at the time of participation. 365 participants practiced a type of meditation (e.g. yoga, mindfulness training), $49.0 \%$ of these more than once a month, $24.9 \%$ more than once a week and $9.6 \%$ daily.

\section{Results}

\subsection{Descriptive Statistics and Reliability}

The total score of the BPS-20 was normally distributed as shown in figure 1a, descriptive statistics are shown on the left side of table 1. To make the scale more efficient it was abridged to 14 items as described below. It remains normally distributed (see figure $1 \mathrm{~b}$ ). Descriptive statistics are shown on the right side of table 1 . The internal consistency of the BPS-20 is acceptable (Cronbach's alpha $=0.71$ ), after abridging the BPS-14 gains a higher internal consistency (Cronbach's alpha $=0.79$ ).

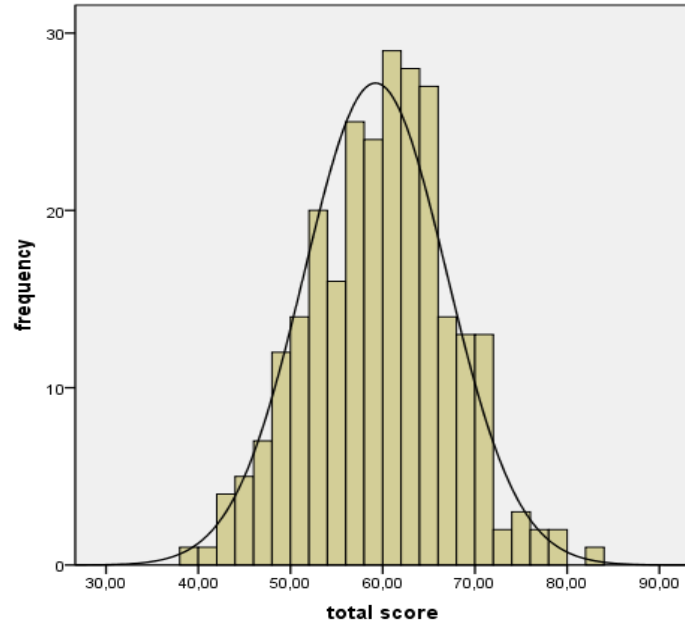

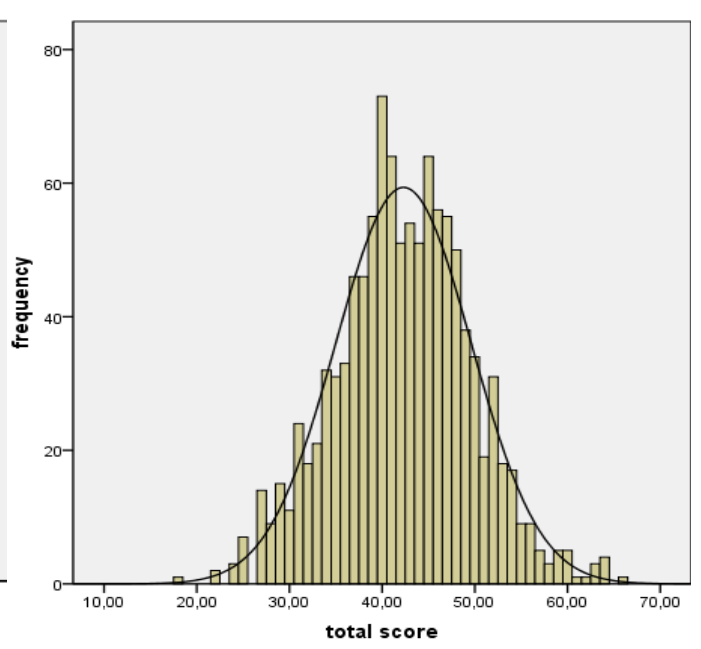

$\mathrm{b}$

Figure 1. Histogram of the BPS-20 (a) and the BPS-14 (b) total scorewith normal curve 
Beside the descriptive statistics we present percentiles as reference values in table 1 so that potential users of this questionnaire are able to make a statement about a particular criterion's manifestation in comparison to a large although unfortunately not representative - sample. There were obvious gender differences with regard to the BPS-20 and -14 total score; males had a lower mean score (i.e. stronger boundary) than females as shown in table 1. Therefore, separate percentiles for males and females are listed in table 1 in addition to the percentiles of the total sample. The score of a mentally healthy person should range between the $25 \%$ and $75 \%$-percentile.

Table 1. Descriptive Statistics and reference values for the BPS-20 and the BPS-14, both total and separate for males and females

\begin{tabular}{lllllll}
\hline & \multicolumn{2}{l}{ BPS-20 } & & \multicolumn{2}{l}{ BPS-14 } \\
& total & male & female & total & male & female \\
\hline number (N) & 1089 & 263 & 826 & 1089 & 263 & 826 \\
total mean score & 62.15 & 59.21 & 63.09 & 42.30 & 40.11 & 43.00 \\
standard deviation (SD) & 8.18 & 7.72 & 8.10 & 7.32 & 7.13 & 7.24 \\
range & 53.00 & 44.00 & 50.00 & 48.00 & 46.00 & 44.00 \\
minimum & 39.00 & 39.00 & 42.00 & 18.00 & 18.00 & 22.00 \\
maximum & 92.00 & 83.00 & 92.00 & 66.00 & 64.00 & 66.00 \\
$\mathbf{5 \%}$ percentile & 49.00 & 46.20 & 50.00 & 30.00 & 29.00 & 31.00 \\
$\mathbf{1 0 \%}$ percentile & 52.00 & 49.00 & 52.70 & 33.00 & 31.00 & 34.00 \\
$\mathbf{2 5 \%}$ percentile & 57.00 & 54.00 & 58.00 & 38.00 & 36.00 & 38.00 \\
$\mathbf{5 0 \%}$ percentile & 62.00 & 60.00 & 63.00 & 42.00 & 40.00 & 43.00 \\
$\mathbf{7 5 \%}$ percentile & 67.00 & 64.00 & 68.00 & 47.00 & 45.00 & 48.00 \\
$\mathbf{9 0 \%}$ percentile & 72.00 & 69.00 & 73.00 & 52.00 & 48.00 & 52.00 \\
$\mathbf{9 5 \%}$ percentile & 75.50 & 71.00 & 76.65 & 54.00 & 51.80 & 54.00 \\
\hline
\end{tabular}

BPS-20: Boundary Protection Scale with 20 items

BPS-14: Boundary Protection Scale with 14 items

Percentile: Percentage of persons in the sample scoring lower.

Because our sample was not representative, we did not calculate reference values for different age groups. However, we found a weak correlation between age and total score $(\mathrm{r}=-0.72, p<0.05)$, with higher scores for persons aged under $40($ mean $=42.51)$ and lower scores for persons aged over $40($ mean $=41.19)$.

\subsection{Abridging the Original Questionnaire}

The following six items were chosen for removal, because they weakened the internal consistency.

"At parties strangers talk to me about their illnesses."

"Friends tell me about their personal problems."

"I share pleasant things with others."

"I have a secret." (inverse item)

"I answer the telephone even if I don't feel like talking."

"If somebody wants to visit me spontaneously at an inconvenient moment, I tell them that I'm busy". (inverse item) 


\subsection{Convergent Validity}

To estimate the convergent validity with the concept of mindfulness the FMI was correlated withthe abridged version (BPS-14) using Spearman's correlation. A moderate correlation between these questionnaires could be found $(\mathrm{r}=-0.48, p<0.001)$, negative as expected, because a high BPS-14 score indicates poor boundary protection, which is assumed to correlate with poor mindfulness (low FMI score).With respect to the subfactors of mindfulness, a medium correlation between the BPS and the acceptance scale was seen $(\mathrm{r}=-0.52, p<0.001)$. This suggests that the BPS-14 measures are especially related to 'acceptance'. Acceptance in the FMI is defined as allowing without judgment or as non-judgmental present experience. The correlations are shown in table 2 .

Table 2. Correlations (Spearman) between the BPS-14 and the FMI with its subscales

\begin{tabular}{lllll}
\hline & BPS & FMI & FMI_Pres & FMI_Acc \\
\hline BPS-14 & 1.00 & $-0.48^{* *}$ & $-0.31^{* *}$ & $-0.52^{* *}$ \\
FMI & & 1.00 & $0.83^{* *}$ & $0.93^{* *}$ \\
FMI_Pres & & & 1.00 & $0.57^{* *}$ \\
FMI_Acc & & & & 1.00 \\
\hline
\end{tabular}

** The correlation is significant at the level 0.001 (bilaterally).

BPS-14: Boundary Protection Scale - 14

FMI: Freiburg Mindfulness Inventory

FMI_Pres: Presence scale of the FMI

FMI_Acc: Acceptance scale of the FMI

Further, weak external validation cues regarding participants with experience with meditation or therapy could be observed. They showed better boundary protection than people with no such experience. Both experience with meditation $(\mathrm{r}=-0.12, p<0.001)$ and experience with therapy $(\mathrm{r}=-0.11, p<0.005)$ were moderately correlated with the BPS.

\section{Discussion}

Our aim was to create a questionnaire measuring the boundary protection as an important part of psychological healthiness and implication of mindfulness. Beside the 20 items version a shorter version with 14 items was created, both normally distributed and offering an acceptable internal consistency. The BPS-14 should be more practical and enable more effective use in the clinical context. Against this background we calculated separate reference values for males and females, as there were gender differences with regard to the mean scores.The self-boundary seems to get stronger along lifetime, because elder individuals showed a better boundary protection in this survey than younger ones. Unfortunately too few individuals were aged over 40 to calculate age separated reference values.

Furthermore, as assumed, a medium correlation between the BPS-14 and the Freiburg Mindfulness Inventory (FMI) was found. This indicates that good boundary protection is related to mindfulness, particularly in terms of acceptance, because this FMI subscale showed the highest correlation with the BPS-14. In other words, people who have learned to accept their inner experiences and sensations are able to remain in and protect their inner world. They can stay connected with their bodily sensations even when these are discomforting physical perceptions. A clearly defined self-boundary allows us to look outwards from within, to simultaneously see the outer world and sense our inner bodily sensations. It is this mindful awareness which makes judgements superfluous. Furthermore, we were able to find first clues for external validation, because meditation and therapy seem to have a weak, but positive, effect on boundary protection.

\subsection{Limitations}

An interesting question is whether mindfulness training helps to develop a strong and clear self-boundary and, in the opposite direction, whether boundary awareness training supports the capability for mindfulness. This could be answered in a long-term study with two different trainings, one for boundary protection and one for mindfulness, but not with the presented data, that gave only a first clue for the relatedness of the two concepts. 
Because the reference values were gained from a sample consisting predominantly of students, they have to be used cautiously. On the one hand, effects of age on the results of the BPS-14 are conceivable, and on the other hand it must be considered that most questionnaires also show differences between groups of varying educational levels. Standardization in a representative sample would be desirable.

\subsection{Perspectives}

The self-boundary is not only an abstract or theoretical concept but also, as we all know, a part of intra- and interpersonal self-experience. We say: "I'm stretched to my limits", "she crossed the line" or "my private life is off-limits", and everyone knows what is meant. Now that terms like feelings, mindfulness or empathy are "in vogue", entirely new questions arise in research, e.g. how are humans able to distinguish their own feelings from those of another and how does this skill develop? What role does the self-boundary play in mindfulness, compassion and empathy skills? What are the possible consequences in this regard if the self-boundary is relatively undeveloped?

In the psychiatric context a relation between child abuse, adult humiliation or being a witness of (a natural) catastrophe and the self-boundary can be assumed (Wöller, 2006). Online social platforms also exert an influence on the development or stabilization of the self-boundary. Are we able to train boundary awareness and to restore or "heal" self-boundaries? As shown above the self-boundary plays a role in the ability to accept within the mindfulness concept of the FMI. In fact, the ability to distinguish between one's own feelings and those of others probably develops quite differently in individuals with psychiatric syndromes. The BPS-14 values could provide therapists with an indication of the severity of traumata (e.g. personality disorders) or delineation problems, seen as a lack of emotional detachment, encroaching behavior, symbiotic relationships or parentification. This may explain why mindfulness-based cognitive therapy in persons with severe life events, whose self-boundary has probably been violated, is less effective in reducing relapse and recurrence (Ma \& Teasdale, 2004). It is difficult to imagine working with the self without working with the self-boundary.

A new instrument like the BPS-14 also enables us to study new issues in "social neuroscience". Is there any neurobiological correlate for the self-boundary? Are we able to determine neurophysiologic changes with anatomical MRI images after directed self-boundary awareness training? Do traumata or repeated boundary violations lead to changes in brain regions that can be specifically associated with self-boundary processing? If so, could they serve to make diagnostic assertions available?

The BPS-14 also allows us to study new questions in the field of sociology. We have already demonstrated a small difference in self-boundary functioning between genders. Are there also differences between generations and do they influence mindfulness capability? Do differences exist between western Europeans and migrants from other cultural environments, between first- and second-generation migrants? Does daily and consistent use of mobile phones, computer games, internet, social networks, or television affect proper functioning of the self-boundary and thus determine the capacity of perception from the inner world?

\subsection{Conclusions}

In this study we investigated a new instrument to measure the protection of the self-boundary. Our results regarding reliability and validity show that the BPS-14 reliably captures the relevant competence. The study shows first indications of a correlation between self-boundary functions and mindfulness, as well as boundary protection and gender. We hope to encourage additional studies to improve the questionnaire further.

Furthermore the BPS-14 invites use not only in the scientific context but also in clinical or psychotherapeutic everyday life. In a society where boundlessness and transparency is becoming more and more common place, as described by Jarvis (2011) and Funk (2011), the BPS-14 could make a useful contribution to generating critical boundary awareness in society.

\section{Acknowledgements}

The authors thank the Samueli Institute of Information Biology (SIIB, VA, USA) for their support as well as the Heiligenfeld Clinics, Bad Kissingen, Germany.

\section{References}

Blaser, K. (2013). Intra- and interpersonal mindful and non-mindful mental states: Comparison of a new spatial attention concept and the IAA mindfulness model of Shapiro. Mindfulness, 4, 64-70. http://dx.doi.org/10.1007/s12671-012-0097-2

Blaser, K. (2012). Aufmerksamkeit und Begegnung: Zwischenmenschliches Aufmerksamkeitsrepertoire, Ich-Grenzen und die Kunst des Zusammenseins. Kröning: Asanger Verlag. 
Blaser, K. (2008). So bin ich und du bist anders, achtsam Grenzen setzen in der Partnerschaft. Freiburg i.B.: Herder Verlag.

Damasio, A. (2010). Self Comes to Mind. Constructing the Conscious Brain. New York: Pantheon Books.

Fonagy, P., Gergely, G., Jurist, E. L., \& Target, M. (2002). Affect Regulation, Mentalization and the Development of the Self. New York: Other Press.

Funk, R. (2011). Der entgrenzte Mensch, warum Leben ohne Grenzen nicht frei, sondern abhängig macht. Gütersloh: Gütersloher Verlagshaus.

Hartmann, E. (1991). Boundaries in the Mind: A New Psychology of Personality. New York: Basic Books.

Heidenreich, T., Ströhle, G., \& Michalak, J. (2006). Achtsamkeit: Konzeptuelle Aspekte und Ergebnisse zum Freiburger Achtsamkeitsfragebogen. Verhaltenstherapie, 16, 33-40. http://dx.doi.org/10.1159/000091521

Hölzel, B. K., Lazar, S. W., Gard, T., Schuman-Olivier, Z., Vago, D. R., \& Ott, U. (2011). How does mindfulness meditation work? Proposing mechanisms of action from a conceptual and neural perspective. Perspectives on Psychological Science, 6, 537-559. http://dx.doi.org/10.1177/1745691611419671

Jarvis, J. (2011). Public Parts. How Sharing in the Digital Age Improves the Way We Work and Live. New York: Simon \& Schuster.

Joraschky, P. (1996). Die System- und Strukturdiagnose. In M. Cierpka (Ed.), Handbuch der Familiendiagnostik. Berlin: Springer-Verlag.

Kohls, N., Sauer, S., \& Walach, H. (2009). Facets of mindfulness - Results of an online study investigating the Freiburg mindfulness inventory. Personality and Individual Differences, 46, 224-230. http://dx.doi.org/10.1016/j.paid.2008.10.009

Lamm, C., Batson, C. D., \& Decety, J. (2007). The neural substrate of human empathy: Effects of perspective-taking and cognitive appraisal. Cognitive Neuroscience, 19, 42-58. http://dx.doi.org/10.1162/jocn.2007.19.1.42

Luhmann, N. (2002). Einführung in die Systemtheorie. Heidelberg: Carl-Auer-Systeme Verlag.

Ma, H. S., \& Teasdale, J. D. (2004). Mindfulness-based cognitive therapy for depression: Replication and exploration of differential relapse prevention effects. Consulting and Clinical Psychology, 72(1), 31-40. http://dx.doi.org/10.1037/0022-006X.72.1.31

Metzinger, T. (2009). The Ego Tunnel. The Science of the Mind and the Myth of the Self. New York: Basic Books.

Rinpoche, S. (2002). The Tibetan Book of Living and Dying. San Francisco: Harper Collins Publisher.

Siegel, D. (2012). Pocket Guide to Interpersonal Neurobiology: An Integrative Handbook of the Mind. New York: W.W. Norton \& Company.

Siegel, D. J. (2007). Mind Your Brain. New York: W.W. Norton \& Company.

Singer, T., \& Lamm, C. (2009). The social neuroscience of empathy. Annals of the New York Academy of Sciences, 1156, 81-96. http://dx.doi.org/10.1111/j.1749-6632.2009.04418.x

Stierlin, H. (1978). Delegation und Familie, Beiträge zum Heidelberger familiendynamischen Konzept. Frankfurt am Main: Suhrkamp Verlag.

Walach, H., Buchheld, N., Buttenmüller, V., Kleinknecht, N., Grossman, P., \& Schmidt, S. (2004). Empirische Erfassung der Achtsamkeit - die Konstruktion des Freiburger Fragebogens zur Achtsamkeit (FFA) und weitere Validierungsstudien. In T. Heidenreich, \& J. Michalak (Ed.), Achtsamkeit und Akzeptanz in der Psychotherapie (pp. 727-770). Tübingen: Deutsche Gesellschaft für Verhaltenstherapie.

Williams, M., Teasdale, J., Segal, Z., \& Kabat-Zinn, J. (2007). The Mindful Way through Depression: Freeing Yourself from Chronic Unhappiness. New York: Guilford Press.

Wöller, W. (2006). Trauma und Persönlichkeitsstörung: Psychodynamisch-integrative Therapie. Stuttgart: Schattauer. 


\section{Appendix}

Appendix 1: Abridged version of the Boundary Protection Scale (BPS-14, translated from the German original)

\section{Boundary Protection Scale - 14}

Please indicate how often you behave in the manner described using the scale to the right of each statement. Please make only one cross in each line.

\section{almost never rarely occasionally frequently}

1
23

4

almost always

\begin{tabular}{|c|c|c|c|c|c|c|c|c|}
\hline 1. & $\begin{array}{l}\text { I would rather say yes than no in } \\
\text { order to avoid conflict }\end{array}$ & O & & O & O & $\mathrm{O}$ & O & \\
\hline 2. & Other people can spoil my pleasure & 0 & & 0 & O & O & O & \\
\hline 3. & I am easily startled & & $\bigcirc$ & O & $\bigcirc$ & O & $\bigcirc$ & \\
\hline 4. & $\begin{array}{l}\text { I often regret saying too much about } \\
\text { myself }\end{array}$ & O & & O & O & O & 0 & \\
\hline 5. & $\begin{array}{l}\text { I don't want to offend others by } \\
\text { saying no }\end{array}$ & $\bigcirc$ & & $\bigcirc$ & O & $\bigcirc$ & O & \\
\hline 6. & $\begin{array}{l}\text { It is OK for me to be doing well, } \\
\text { even if another person is currently } \\
\text { not doing so well }\end{array}$ & O & & O & $\bigcirc$ & O & 0 & \\
\hline 7. & $\begin{array}{l}\text { I know when it is the right moment } \\
\text { to change the topic }\end{array}$ & $\bigcirc$ & & $\bigcirc$ & O & $\bigcirc$ & O & \\
\hline 8. & I have a witty answer ready & O & & 0 & 0 & O & 0 & \\
\hline 9. & I do not take on what others say & O & & 0 & 0 & $\bigcirc$ & 0 & \\
\hline 10 & $\begin{array}{l}\text { When I say no it can easily be } \\
\text { turned into a yes }\end{array}$ & 0 & & O & 0 & 0 & O & \\
\hline 11 & $\begin{array}{c}\text { I answer questions even when I } \\
\text { don't actually want to answer them }\end{array}$ & O & & $\bigcirc$ & O & $\bigcirc$ & 0 & \\
\hline 12 & I take on too many obligations & & O & 0 & 0 & O & & O \\
\hline 13 & $\begin{array}{l}\text { A negative group atmosphere } \\
\text { influence's my own mood }\end{array}$ & O & & 0 & 0 & 0 & O & \\
\hline 14 & $\begin{array}{l}\text { I find arguments between friends, } \\
\text { my parents or colleagues stressful }\end{array}$ & O & & O & 0 & O & 0 & \\
\hline
\end{tabular}

\section{Copyrights}

Copyrights for this article are retained by the author, with first publication rights granted to the journal. This is an open-access article distributed under the terms and conditions of the Creative Commons Attribution license (http://creativecommons.org/licenses/by/3.0/). 